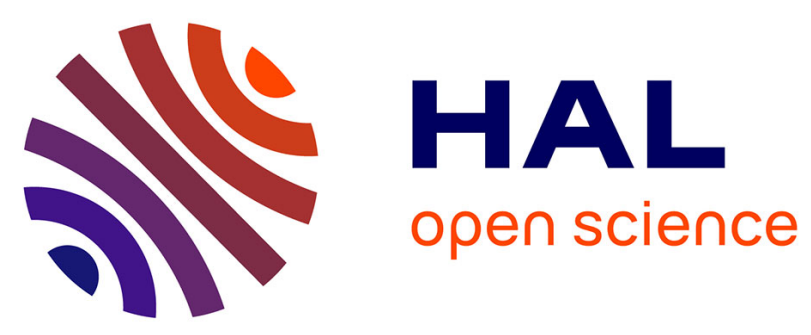

\title{
Identification of novel genes and altered signaling pathways in the retinal pigment epithelium during the Royal College of Surgeons rat retinal degeneration
}

\author{
Eric M. Dufour, Emeline Nandrot, Dominique Marchant, Loic van den \\ Berghe, Stéphanie Gadin, Moussa Issilame, Jean-Louis Dufier, Cécile Marsac, \\ Deborah Carper, Maurice Menasche, et al.
}

\section{To cite this version:}

Eric M. Dufour, Emeline Nandrot, Dominique Marchant, Loic van den Berghe, Stéphanie Gadin, et al.. Identification of novel genes and altered signaling pathways in the retinal pigment epithelium during the Royal College of Surgeons rat retinal degeneration. Neurobiology of Disease, 2003, pp.166-180. hal-03086809

\section{HAL Id: hal-03086809 https://hal.science/hal-03086809}

Submitted on 17 Nov 2021

HAL is a multi-disciplinary open access archive for the deposit and dissemination of scientific research documents, whether they are published or not. The documents may come from teaching and research institutions in France or abroad, or from public or private research centers.
L'archive ouverte pluridisciplinaire HAL, est destinée au dépôt et à la diffusion de documents scientifiques de niveau recherche, publiés ou non, émanant des établissements d'enseignement et de recherche français ou étrangers, des laboratoires publics ou privés. 


\title{
Identification of novel genes and altered signaling pathways in the retinal pigment epithelium during the Royal College of Surgeons rat retinal degeneration
}

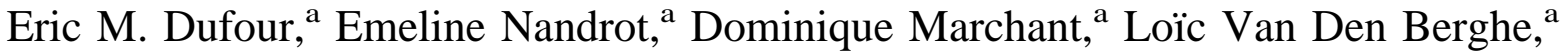 \\ Stéphanie Gadin, ${ }^{a}$ Moussa Issilame, ${ }^{a}$ Jean-Louis Dufier, ${ }^{a}$ Cécile Marsac, ${ }^{a}$ Deborah Carper, ${ }^{b}$ \\ Maurice Menasche, ${ }^{\mathrm{a}}$ and Marc Abitbol ${ }^{\mathrm{a}, *}$ \\ ${ }^{a}$ CERTO, Équipe d'accueil n²502 du Ministère de la Recherche, Université René Descartes, \\ Faculté de Médecine Necker, 156 rue de Vaugirard 75015 Paris \\ ${ }^{\mathrm{b}}$ Section on Molecular Therapeutics, National Eye Institute, National Institutes of Health, Bethesda, MD, USA
}

Received 21 October 2002; revised 27 March 2003; accepted 28 May 2003

\begin{abstract}
Shed photoreceptor outer segments (POS) are phagocytosed by RPE cells in a circadian manner. The homozygous deletion of the c-mer gene abolishes the ingestion phase of this phagocytosis in the Royal College of Surgeons (RCS) rat strain, which in turn leads to the death of photoreceptor cells. We identified RPE transcripts for which the expression is modulated by the abrogation of POS phagocytosis. A microarray approach and the differential display (DDRT-PCR) technique revealed 116 modulated known genes, 4 modulated unknown genes, and 15 expressed sequenced tags (ESTs) corresponding to unknown genes. The microarray and DDRT-PCR analyses detected alterations in signaling pathways such as the phosphatidylinositol 3-kinase-Akt-mTOR pathway and the DLK/JNK/SAPK pathway. The abrogation of POS phagocytosis caused a decrease in endomembrane biogenesis and altered endocytosis, exocytosis, transcytosis, and several metabolic and signaling pathways in RCS RPE cells. We also found differential levels of transcripts encoding proteins involved in phagocytosis, vesicle trafficking, the cytoskeleton, retinoic acid, and general metabolism.
\end{abstract}

(C) 2003 Elsevier Inc. All rights reserved.

Keywords: RCS rat; Phagocytosis; Differential display; Microarray; Retinal pigment epithelium; Gene expression

\section{Introduction}

In the retina, the phototransduction is carried out by photoreceptors (PR) using opsin proteins contained in cone or rod photoreceptor outer segments (POS). The POS consist of discs that originate from continuous membrane lamellae refolding. PR ensure their own functionality by replacing their outer segments on a daily basis. Packets of shed POS discs are engulfed by the retinal pigment epithelium (RPE), which recycles the components of the phototransduction machinery (Herron et al., 1969). This phago-

\footnotetext{
* Corresponding author. CERTO, Faculté de Médecine Necker-Enfants Malades, 156 rue de Vaugirard, 75015 Paris, France. Fax: +00-33-1-4061-54-74.

E-mail address: abitbol@necker.fr (M. Abitbol).
}

cytosis phenomenon follows a circadian rhythm (LaVail, 1976), occurring just after the onset of light and dark each day. The integrity of the PR depends on numerous functions carried out by the RPE, such as protection against high intensity light, the outer blood-retinal barrier, the selective transport of metabolites to the neural retina, the synthesis of the interphotoreceptor extracellular matrix and, mostly on the phagocytosis and recycling of POS.

The Royal College of Surgeons (RCS) $r d y-$ (for Retinal Dystrophy) rat strain was the first spontaneous animal model of inherited retinal pigment epithelium defect to be described (Bourne et al., 1938) and is one of the major animal models for human retinitis pigmentosa (RP). In the RCS rat retina, the circadian phagocytosis of shed POS by the RPE is abolished (Mullen and LaVail, 1976). Conse- 
quently, POS fragments accumulate, leading to the degeneration of photoreceptor cells between 18 days and 3 months after birth and the loss of vision (Dowling and Sidman, 1962). A number of studies have shown that the PR cells develop normally until 15 days of age, although ultrastructural studies subsequently showed that the tips of the PR are disorganized in the 10-day-old rat retina (Bok and Hall, 1971). The phagocytosis defect in RCS rats is caused by a deletion in the c-mer gene (D'Cruz et al., 2000; Nandrot et al., 2000). As the RCS RPE binds shed photoreceptor tips without ingesting them (Hall and Abrams, 1987), the c-mer receptor might be responsible for the internalization step of POS phagocytosis.

We used two different techniques to identify genes with modulated expression that might be involved in phagocytosis or associated with other dysfunctions of the RPE. The first technique was the microarray technology and the second was the mRNA differential display (DDRT-PCR). Recent advances in microarray technology have made it possible to monitor a large number of known and unknown genes simultaneously. The oligonucleotide chip technique permits the investigation of the expression profiles of more than 8000 sequences. The DDRT-PCR technique was originally described 10 years ago (Liang and Pardee, 1992) and is a rapid method for identifying differences in mRNA levels between identical tissues, receiving or not an experimental treatment, or differing ideally only by a single defect. It involves the use of different anchored oligo(dT)VN primers and random primers to amplify cDNA fragments representing a subset of expressed genes. This method has been successfully used to identify numerous novel and known transcripts that are differentially expressed in various biological systems (Pierce et al., 1999).

Our aim was to study modulations in gene expression levels induced by the lack of phagocytosis in RCS rats compared to normal rats. This is the first global study on this defect of photoreceptor outer segment phagocytosis. The microarray technique was used on 2-week-old rats to study the impact of the lack of phagocytosis on the developing RCS retina, before it starts to manifest any microscopically detectable signs of photoreceptor degeneration. DDRTPCR was performed on 3-week-old rats, an age at which photoreceptors begin to degenerate. All modulations of gene expression detected by both methods were further studied in 2- and 3-week-old RCS and control RPE cells using semiquantitative PCR (sqPCR). We hypothesized that the characterization of the differences in gene expression might enable us to identify genes involved in the process of ROS phagocytosis or RPE homeostasis. At least some genes that display altered RPE expression due to the c-mer homozygous deletion might constitute new candidate genes for RP or age-related macular degeneration (AMD).

\section{Materials and methods}

All animals were handled in strict accordance with the ARVO Resolution on the Use of Animals in Ophthalmic

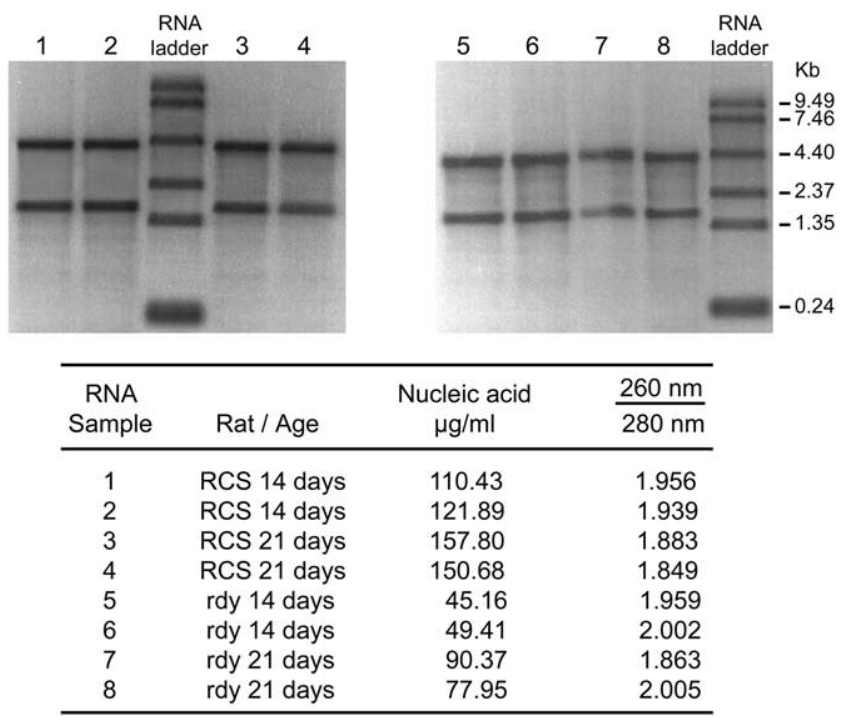

Fig. 1. Picture of the $1 \%$ agarose gel after migration of the total RNAs collected for each group of animals and table figuring the optical densities for the sample absorbances at 260 and $280 \mathrm{~nm}$.

and Vision Research. The animals were kept at $21^{\circ} \mathrm{C}$ with a 12-h light/12-h dark cycle and were fed ad libitum. All animals were killed by $\mathrm{CO}_{2}$ asphyxiation.

\section{RNA extraction}

Pigmented congenic control and dystrophic RCS rats were killed at the age of 14 days, just after the opening of the eyelids, or at the age of 21 days. All animals were killed between 1 and $2.5 \mathrm{~h}$ after the beginning of the light period, when rod outer segment phagocytosis is maximal. Rats were rapidly enucleated. The cornea, iris, and lens were quickly removed with scissors and forceps, and the neural retina was taken out. The RPE monolayer was swiftly isolated together with the adhesive Bruch's membrane by scraping with small spatula. The cells collected were recovered in lysis buffer and frozen in liquid nitrogen. Total RNAs were isolated with the RNeasy mini kit (Qiagen S.A., France) and treated with DNase I (Qiagen S.A.) according to the manufacturer's protocol. The integrity, quality, and spectral analysis of the RNAs were verified using DU 640i Beckman Coulter (France S. A. Paris Nord II) spectrophotometer measurements and by the analysis of $1 \%$ agarose gel electrophoresis. The quantification of the amount of total RNAs could be made on the basis of the calculation of the optical densities of each sample (Fig. 1). No differences in RNA quality were detected between the groups of animals studied. The type of animal termination chosen for our study is required for ethical reasons by our institution and eventually has minimal confounding effects on global RPE gene expression pattern. The duration of the RPE cells microdissection is the critical parameter for decreasing any hypoxia-induced effects and was reduced to the minimal time compared to the time required by the termination procedure. Whatsoever, 
RCS and rdy rats were submitted to the same termination procedure. As strict and extremely swift procedures were followed by our team for obtaining total RNAs from each strain of animals, we can confidently trust the validity of the data obtained.

\section{Microarrays}

Double-strand cDNAs were synthesized from total RPE RNA from 15-day-old rats by use of the Superscript Choice System (Invitrogen SARL, France). Briefly, $10 \mu \mathrm{g}$ of total RNA from RPE cells was incubated for 10 min at $70^{\circ} \mathrm{C}$ with 100 pmol of T7-(dT)24 primer (Affymetrix) in an $11 \mu \mathrm{l}$ reaction volume. RNAs were incubated with first-strand cDNA buffer, $10 \mathrm{mM}$ DTT, and $500 \mu \mathrm{M}$ of each dNTP for $2 \mathrm{~min}$ at $42^{\circ} \mathrm{C}$. Then, $400 \mathrm{U}$ of Superscript II (Invitrogen SARL, France) were added and the samples were incubated at $42^{\circ} \mathrm{C}$ for $1 \mathrm{~h}$. To synthesize the second strand, $10 \mathrm{U}$ of DNA ligase, $40 \mathrm{U}$ of DNA polymerase I, $2 \mathrm{U}$ of RNase H, $200 \mu \mathrm{M}$ of each dNTP, and the second-strand reaction buffer were directly added in a final volume of $150 \mu$ l. The tubes were incubated at $16^{\circ} \mathrm{C}$ for $2 \mathrm{~h}$. After adding $10 \mathrm{U} \mathrm{T} 4$ DNA polymerase, the samples were incubated at $16^{\circ} \mathrm{C}$ for 5 $\mathrm{min}$. The cDNAs were then cleaned up by a phenol/chloroform extraction and resuspended in $12 \mu \mathrm{l}$ of RNase-free water.

cDNAs were mixed with biotin-labeled ribonucleotides, DTT, RNase inhibitor mix, and T7 RNA polymerase (Roche-Boehringer, Switzerland) and were incubated for $5 \mathrm{~h}$ at $37^{\circ} \mathrm{C}$. The RNA Transcript Labelling Kit (ENZO) was used for this in vitro transcription step to produce biotin-labeled cRNAs.

The cRNA samples were cleaned up with RNeasy Spin columns (Qiagen S.A.) and their integrity was checked on a $1 \%$ agarose gel. cRNAs were fragmented and hybridized by Affymetrix Research Genetics Laboratories (www. affymetrix.com). Once the probe array had been hybridized, stained and washed, it was scanned twice. Data were analyzed using GeneChip Expression Analysis Window software (Affymetrix) and the Array Suite 5.0 software (Affymetrix UK Ltd, England).

\section{$m R N A$ differential display $R T-P C R$}

DDRT-PCR was performed using the Hieroglyph mRNA Profile for Differential Display Analysis Kit (Genomyx Corporation), according to the manufacturer's instructions. cDNAs were synthesized from $0.2 \mu \mathrm{g}$ of total RPE RNA from 21-day-old rats from each strain. RNAs were mixed with $0.2 \mathrm{mM}$ of each of the 12 primers (T7 anchored(dT) $11 \mathrm{NV}$ ), incubated at $70^{\circ} \mathrm{C}$ for $10 \mathrm{~min}$, and cooled. The reverse transcription reaction was initiated by incubating at $37^{\circ} \mathrm{C}$ for $1 \mathrm{~h}$ in the presence of a mixture containing 40 units of Superscript II polymerase (Life Technologies). The enzymes were then inactivated at $70^{\circ} \mathrm{C}$ for $10 \mathrm{~min}$.

The cDNAs were labeled during PCR amplification us- ing $0.2 \mathrm{mM}$ of the appropriate oligo-(dT) $11 \mathrm{NV}$ and one of the 20 arbitrary primers (M13 anchored-10 mers, Hieroglyph mRNA Profile for Differential Display Analysis Kit (Genomyx C) with $3 \mathrm{mM} \mathrm{MgCl} 2,20 \mathrm{mM}$ of each dNTP, 2.5 $\mu \mathrm{Ci} \alpha$-dATP ${ }^{33} \mathrm{P}$, and $1 \mathrm{U}$ of AmpliTaq DNA polymerase (Perkin Elmer France, France). The amplification conditions were $15 \mathrm{~s}$ at $95^{\circ} \mathrm{C}$, followed by $30 \mathrm{~s}$ at $50^{\circ} \mathrm{C}$, and $2 \mathrm{~min}$ at $72^{\circ} \mathrm{C}$ for 4 cycles, and then $15 \mathrm{~s}$ at $95^{\circ} \mathrm{C}, 30 \mathrm{~s}$ at $60^{\circ} \mathrm{C}$, and 2 min at $72^{\circ} \mathrm{C}$ for 25 cycles. All PCRs were performed in duplicate to ensure reproducibility. Samples from each amplification reaction were loaded onto an $8 \%$ polyacrylamide-urea DNA sequencing gel and run at $8 \mathrm{~W}$ for $16 \mathrm{~h}$. The gels were then processed for autoradiography. Only bands that were consistently different were considered. These bands were excised from the gel and the cDNA was eluted in water after heating at $95^{\circ} \mathrm{C}$ for $5 \mathrm{~min}$.

\section{Single-strand conformation polymorphism (SSCP)}

To identify true positive cDNA fragments, we screened the amplified cDNAs using SSCP gels. Individual cDNA fragments were reamplified using the same protocol described above, except that we used M13 and T7 primers ( 0.2 $\mathrm{mM}$ ) (Genomyx) and $1 \mu \mathrm{Ci}$ of $\alpha$-dATP ${ }^{33} \mathrm{P}$. The bands carrying differentially expressed products and the region of the gel corresponding to the adjacent lane where the product was less prominent or not visible were reamplified. PCR products were heated at $95^{\circ} \mathrm{C}$ for $5 \mathrm{~min}$ and loaded onto a $5 \%$ nondenaturing polyacrylamide gel. After electrophoresis at $5 \mathrm{~W}$, the gels were dried and exposed to X-ray films (Kodak, France).

\section{Cloning and sequencing}

True positive cDNA fragments were excised from the gel and cDNA was eluted in water as described above. Individual cDNA fragments were reamplified using the M13 and T7 primers. The amplified products were directly cloned using pGEM-T Easy Vector (Promega France). Clones were isolated, sequenced, and analyzed on an ABI PRISM 310 genetic analyzer (PE Applied Biosystem, France). The sequences of the selected genes were compared to those in the GenBank database.

\section{Elongation of unknown sequences}

Full-length cDNA was obtained by using the SMART RACE cDNA Amplification kit (Clontech) according to the manufacturer's protocol. 5' and 3' RACE PCRs were performed for each sequence.

\section{Semiquantitative PCR}

To determine whether candidate genes were differentially expressed, specific oligonucleotides were synthesized by QbioGene (France). Semiquantitative PCR was per- 
formed at both ages ( 2 and 3 weeks) with an internal expression control. The cDNAs were amplified in a mixture containing $1.5 \mathrm{mM} \mathrm{MgCl} 2,200 \mu \mathrm{M}$ of each dNTP, 1 to 10 $\mu \mathrm{M}$ of the candidate gene primers, 0.1 to $1 \mu \mathrm{M}$ of the control gene primer (cyclophilin A or the Ribosomal protein $\mathrm{P} 0$ gene), and $1 \mathrm{U}$ of AmpliTaq DNA polymerase (Perkin Elmer France). The cycle conditions were as follows: $92^{\circ} \mathrm{C}$ for $2 \mathrm{~min}$, followed by 20 to 30 cycles of $30 \mathrm{~s}$ at $92^{\circ} \mathrm{C}, 30 \mathrm{~s}$ at $55^{\circ} \mathrm{C}$, and $1.5 \mathrm{~min}$ at $72^{\circ} \mathrm{C}$, and a final extension step of $7 \mathrm{~min}$ at $72^{\circ} \mathrm{C}$. PCR products were verified on $1.5 \%$ agarose gels, and all the bands were quantified with the Scion Image software and normalized according to the internal control band.

\section{Immunohistochemistry}

Following deparaffination and rehydratation, 2-, 3-, and 5 -week-old rat eye sections were incubated for $20 \mathrm{~min}$ in $1 \mathrm{X}$ Citrate buffer in a $350-\mathrm{W}$ microwave oven. Sections were then treated with $3 \% \mathrm{H}_{2} \mathrm{O}_{2}$ for $10 \mathrm{~min}$, washed three times in PBS, incubated with $0.3 \%$ Triton for $10 \mathrm{~min}$, and then with normal swean serum (DAKO, France) for $15 \mathrm{~min}$. The sections were exposed at $+4^{\circ} \mathrm{C}$ to a mouse monoclonal anti-rat Paxillin-kinase linker (BD Transduction Laboratories) or a mouse monoclonal anti-rat Grasp55 (BD Transduction Laboratories) at a final dilution of $1 \mu \mathrm{g} / \mathrm{ml}$ in an antibody diluant (DAKO). After four washings in PBS, slides were incubated with a horseradish peroxidase (HRP)coupled secondary antibody (DAKOChemMate; DAKO) for $30 \mathrm{~min}$ at room temperature. Immunostaining was visualized using a Peroxidase/Diaminobenzidine Detection Kit (DAKOChemMate; DAKO). Sections were finally mounted with Eukitt (PolyLabo, France).

\section{Results}

\section{Analysis of transcripts in the 14-day-old rat RPE}

The commercially available Affymetrix GeneChip probe arrays combine photolithographic methods and combinatorial chemistry. Tens to hundreds of thousands of different oligonucleotide probes are synthesised on each array (Lipshutz et al., 1999). Probes are 25-base-long single-stranded DNA oligonucleotides, complementary to a specific sequence. Each probe pair consists of a "perfect match" probe and a "mismatch" probe, which contains a mutation at the central (13th) position and serves as a negative control. Between 16 and 20 regions of each gene sequence are used as probe pairs to enable a detailed and a statistically significant study of the expression and the possible modulations of each gene. The number of instances in which the perfect match (PM) hybridization signal is larger than the mismatch (MM) signal is calculated along with the average of the logarithm of the PM:MM ratio (after background substraction) for each probe set. These values are then used to make a matrix-based decision as to whether each RNA transcript is present or absent in the control. The average difference serves as a relative indicator of the level of expression of a transcript and can be used to determine the change in the hybridization intensity of a given probe set in different experiments. We performed $2 \times 3$ pairwise comparisons. The meaning and relevance of the fold change should be considered according to whether the transcript is present or absent at baseline.

Clustering or, more accurately, categorization of our microarray data was performed by using direct visual inspection to group together genes with similar functions and expression patterns. This method is best suited to instances in which the patterns of interest are clear in advance, such as the lack of phagocytosis. Intensive analyses were done with the Unigen, GenBank, TIGR databases and on the http://rgd.mcw.edu/;http://ratmap.gen.gu.se/; http://www.ncbi.nlm.nih.gov/genome/guide/Rnorvegicus. html; http://ratmap.ims.u-tokyo.ac.jp/; http://bodymap.ims. u-tokyo.ac.jp sites.

We used Affymetrix oligonucleotide microarrays to characterize early molecular genetics signs of retinal dysfunction in 2-week-old rats. A total of 8801 oligonucleotides were used in these arrays, 5373 of which corresponded to known genes and 3428 of which originated from expressed sequence tags (ESTs). Nevertheless, some redundancies existed and the 8801 oligonucleotides did not correspond to 8801 different genes.

Two different computer programs were used to analyze the microarray results. These programs used two different algorithms. The first algorithm was impair based. It included previous results obtained with the same microarrays in different biological situations and can therefore be considered to be semiempirical. The second algorithm was exclusively based on statistical tests and can be considered to be a mathematical algorithm. With the GeneChip Expression Analysis Window software, 3700 of the 8801 sequences were present in the RPE of control rats, and 5101 were absent. In the RCS RPE, the expression of 317 genes was modulated: the expression of 125 known genes or EST sequences decreased and that of 192 increased. As a balanced differential expression of 2-fold or more has been shown to be significant (Guo et al., 2000; Heller et al., 1997), we further characterized the sequences from 84 known genes that matched this criterion. In these conditions, the expression of 49 known genes decreased and that of 35 transcripts increased in RCS rats. The second program, Array Suite 5.0, uses an algorithm based on statistical tests to look for genes that are strongly modulated ( $\geq 2$-fold change). We found that the expression of 63 known genes was modulated. Using this software, the expression of 44 known genes decreased and that of 19 increased in the RCS rat RPE. In total, 110 different modulated known genes were identified by these two methods (Table 1). The genes identified by both analyses are shown in Table 2 . We also 
Table 1

Modulation of gene expression in 14-day-old RPE between RCS and congenic controls

\begin{tabular}{|c|c|c|c|c|}
\hline Genbank & Change & Name & Function & So \\
\hline \multicolumn{5}{|l|}{ Transcription } \\
\hline AI014135 & -2 & CDK109 & Similar to mitochodrial $16 \mathrm{~S}$ RNA & 1 \\
\hline U94340 & -6.4 & ADP-ribosyltransferase & Polymerase & 2 \\
\hline U32577 & -33.5 & ribonucleoprotein M4 & RNA splicing and packaging & 2 \\
\hline AI231164 & -2 & Splicing factor Sfrs 10 & Splicing factor & 2 \\
\hline L09656 & -2 & Tcf12 & Splicing factor & 2 \\
\hline AA875069 & -3.6 & Histone $\mathrm{H} 3 \mathrm{~b}$ & Chromatin & B \\
\hline X89383 & -2.2 & SNF1 kinase & Histone kinase & B \\
\hline \multicolumn{5}{|l|}{ Translation } \\
\hline U11071 & -2 & Polyadenylate-binding protein & ARN stabilisation/degradation & 1 \\
\hline X60212 & -2.2 & ASI large ribosomal protein L22 & Translation & 1 \\
\hline X59051 & -2.1 & Ribosomal protein S29 & Translation & 1 \\
\hline RNU20525 & -2.1 & Lens epithelial protein & Translational control & 1 \\
\hline AI103498 & -2.3 & Ribosomal protein L5 & Translation & 2 \\
\hline X15216 & -2 & Ribosomal protein L21 & Translation & 2 \\
\hline AA892801 & -8.1 & Elongation factor 2 & Translation & B \\
\hline AI008852 & -3.3 & Elongation factor 1 alpha & Translation & B \\
\hline \multicolumn{5}{|c|}{ Oxygen metabolism } \\
\hline X56325 & -2.7 & 2-alpha-1 globin & Oxygen carrier & 1 \\
\hline J01435 & -2.7 & mit. COX subunits I, II, III & Respiration & 1 \\
\hline M94919 & -3.4 & Beta-globin gene & Oxygen carrier & 1 \\
\hline Y09507 & -2.6 & HIF1 alpha & Hypoxia response & 2 \\
\hline M27467 & -2 & Heart COX VIc & Respiration & B \\
\hline \multicolumn{5}{|l|}{ Phagocytosis } \\
\hline U57500 & -2 & Tyrosine phosphatase alpha (PTPRA) & Signaling, Grb2 pathway & 1 \\
\hline Y12635 & -3.8 & Vacuolar ATPase subunit B & Phagosome/lysosome fusion & 1 \\
\hline Y12635 & -2.1 & ATP6b2 transporter & lysosomal acidification & 2 \\
\hline S81353 & -2.4 & Sulfated glycoprotein-1/saposine & Phagosome/lysosome lipid degradation & $\mathrm{B}$ \\
\hline D84477 & -2.4 & RhoA & Signaling & B \\
\hline U03763 & -2.4 & Phospholipase A2 & Lysome lipid degradation & B \\
\hline X76489 & -2.1 & CD9 glycoprotein & Fusion/engulfment & B \\
\hline U88324 & -2.4 & Protein G beta 1 (Gnb1) & Signaling & B \\
\hline AF041066 & -2 & Ribonuclease 4 & Lysome & B \\
\hline \multicolumn{5}{|l|}{ Cellular traffic } \\
\hline X06655 & -2.5 & synaptophysin vesicle protein $\mathrm{p} 38$ & Exocytosis & 1 \\
\hline L10362 & -2 & Synaptic vesicle $S v 2 b$ & Exocytosis & 2 \\
\hline M15882 & -2.7 & Clathrin light chain & Endocytosis & 2 \\
\hline M15883 & -2.3 & Clathrin light polypeptide & Endocytosis & 2 \\
\hline X92097 & -2.1 & Coated vesicle rnp21.4 & Vesicular traffic & B \\
\hline L13445 & -2.4 & Syalyltransferase 8 & Golgi & B \\
\hline \multicolumn{5}{|c|}{ Endoplasmic reticulum } \\
\hline AF100470 & -5.6 & RAMP4 & Chaperon protein & 1 \\
\hline X52817 & -2.1 & Reticulon 1 & Potential recycling & 1 \\
\hline L15618 & -2.6 & Casein kinase 2 & Multifunction kinase & 2 \\
\hline AA685903 & -2.9 & GRP94/endoplasmin & Chaperon protein & B \\
\hline \multicolumn{5}{|l|}{ Matrix proteins } \\
\hline NM012862 & -2.5 & Matrix Gla protein & Tissue calcification inhibitor & 1 \\
\hline AI231292 & -2.1 & Cystatin C & Cystein proteases inhibitor & 1 \\
\hline U27201t & -2.4 & TIMP-3 & Metalloproteinases inhibitor & 1 \\
\hline \multicolumn{5}{|c|}{ Membrane proteins } \\
\hline X53054 & -5.7 & RT1.D beta chain & MHC I & 2 \\
\hline AA818982 & -3.2 & Thymopoeitin & Inner nuclear membrane & 2 \\
\hline AA818970 & -2.6 & Endothelin receptor B & Cell growth & 2 \\
\hline AI228669 & -3.4 & GABA transporter & Lysosome & 2 \\
\hline X77934 & -4.5 & Aplp2 & Amyloid like-protein & $\mathrm{B}$ \\
\hline M74494 & -2.9 & $\mathrm{Na}+\mathrm{K}+$ ATPase & Ions transporter & B \\
\hline Z54212 & -2.6 & Emp1 & Cell-cell interaction & B \\
\hline \multicolumn{5}{|l|}{ Cytoskeleton } \\
\hline NM007393 & -2 & Melanoma $\mathrm{X}$ actine & Membrane ruffling & 1 \\
\hline AF084186 & -3 & Spectrin (Spna2) & Membrane structure & 2 \\
\hline A1070848 & -2.1 & Cytoplasmic beta actin & Membrane ruffling & 2 \\
\hline AF122902 & -2.8 & beta actine & Membrane ruffling & B \\
\hline \multicolumn{5}{|l|}{ Lipid } \\
\hline X04979 & -2 & Apolipoprotein E & Lipid carrier & 1 \\
\hline X98225 & -2.4 & Gastrin-binding protein (Hadha) & Fatty acids oxydation & 1 \\
\hline U67995 & -2.4 & Steoaryl-CoA desaturase 2 & Fatty acids synthesis & B \\
\hline
\end{tabular}


Table 1 (continued)

\begin{tabular}{|c|c|c|c|c|}
\hline Genbank & Change & Name & Function & Software ${ }^{a}$ \\
\hline \multicolumn{5}{|l|}{ Metabolism } \\
\hline X60328 & -3.4 & Cytosolic epoxide hydrolase & Detoxification & 1 \\
\hline M19257 & -2 & CRBP & retinol carrier & 1 \\
\hline D38380 & -2.7 & Transferrin & Iron carrier & 1 \\
\hline D86641 & -2 & FK506-binding protein $12 / \mathrm{mTOR}$ & Protein expression & 1 \\
\hline AA945169 & -3.1 & Transthyretin & Thyroid hormone/retinol carrier & 1 \\
\hline D49785 & -4 & Map3K12/DLK & Stress signaling & 2 \\
\hline M21476 & -5.3 & Iodothyronine 5-monodeiodinase & Thyroid hormone metabolism & $\mathrm{B}$ \\
\hline M93297 & -2 & Ornithine aminotransferase & Aminoacids metabolism & $\mathrm{B}$ \\
\hline U35774 & -2.2 & Bcat1 & Aminoacids metabolism & $\mathrm{B}$ \\
\hline AA924326 & -2.2 & Aldolase A & Glycolysis & $\mathrm{B}$ \\
\hline AF106860 & -2 & GAPDH & Glycolysis & $\mathrm{B}$ \\
\hline M24852 & -2.6 & PEP19 & Synaptogenesis ?? & B \\
\hline \multicolumn{5}{|l|}{ Transcription } \\
\hline D67015 & +3.3 & SCG (Importin beta) & Protein transport to the nucleus & 1 \\
\hline AA849035 & +3.1 & B myc & Transcription factor & 1 \\
\hline AB012234 & +2.2 & NF1-X1 & Transcription factor & 1 \\
\hline X56546 & +2.7 & vHNF1 & Transcription factor & 1 \\
\hline U25746 & +2.1 & Helicase Arg-Ser-rich domain & RNA processing & 1 \\
\hline $\mathrm{U} 21719$ & +2.5 & D 920 Epithelium proliferating & Proliferating cells associated mRNA & 1 \\
\hline AI012183 & +4 & Nrf2 & Transcription factor & $\mathrm{B}$ \\
\hline U10995 & +2 & $\mathrm{Nr} 2 \mathrm{f} 1$ & Transcription factor & $\mathrm{B}$ \\
\hline \multicolumn{5}{|c|}{ Oxidative stress } \\
\hline AA859934 & +3.5 & DNAJ protein like (Hsp 40) & Protein renaturation after stress & 1 \\
\hline D15069 & +2.7 & Adrenomedullin precursor & Hypoxia response & 1 \\
\hline X64589 & +3.9 & Cyclin B & Hypoxia response & 1 \\
\hline AA926149 & +2.3 & Catalase & Oxidative stress, hypoxia response & $\mathrm{B}$ \\
\hline AI233261 & +3.2 & Glutamate-cystein ligase (Gclm) & Oxidative stress, hypoxia response & $\mathrm{B}$ \\
\hline \multicolumn{5}{|c|}{ Endoplasmic reticulum } \\
\hline AA800930 & +3.4 & Aspartyl beta hydrolase (Asph) & $\mathrm{Ca}^{2+}$ binding protein & 1 \\
\hline U15734 & +2.1 & Reticulocalbin 2 & $\mathrm{Ca}^{2+}$ binding protein & $\mathrm{B}$ \\
\hline \multicolumn{5}{|l|}{ Phagocytosis } \\
\hline rx02826 & +2.2 & CED6 & Apoptotic particles clearance & 1 \\
\hline S63521 & +2.3 & GRP78 & Chaperon protein/phagosomes & $\mathrm{B}$ \\
\hline AI236721 & +3.6 & $14-3-3$ & Kinase associated phagosomes & $\mathrm{B}$ \\
\hline \multicolumn{5}{|l|}{ Matrix proteins } \\
\hline AA799755 & +5.1 & ACLP (AE binding protein 1) & Adhesion & 1 \\
\hline X84039 & +2.2 & Lumican & Growth suppression & 2 \\
\hline X59859 & +3 & Decorin & Growth suppression & $\mathrm{B}$ \\
\hline \multicolumn{5}{|l|}{ Cell signaling } \\
\hline L13619 & +2.7 & CL-6 & Growth response & 1 \\
\hline S40803 & +3.1 & Luteinizing hormone receptor & Growth factor & 1 \\
\hline AF064868 & +5.8 & Begain & Nucleus & 1 \\
\hline AF102855 & +5.3 & Synamon protein & Postsynaptic protein & 1 \\
\hline L20678 & +4.2 & BMP2 & Growth factor & 1 \\
\hline M81183 & +3.8 & IGF1 & Growth factor & $\mathrm{B}$ \\
\hline \multicolumn{5}{|l|}{ Cytoskeleton } \\
\hline AA900769 & +2.2 & smooth muscle actin alpha 2 & Membrane structure & 2 \\
\hline X05566 & +3.4 & Myosin regulatory light chain & Membrane structure & $\mathrm{B}$ \\
\hline \multicolumn{5}{|l|}{ Metabolism } \\
\hline L07114 & +3.3 & Apolipoprotein B & Lipid carrier & 1 \\
\hline D82883 & +2.2 & Sulfate transporter & Sulfate carrier & 1 \\
\hline Y16774 & +2.0 & Dri 27/ZnT4 Zinc transporter & Zinc carrier & 1 \\
\hline U21662 & +15 & Mannosyl(alpha1-6) Mgat2 & Golgi & 2 \\
\hline AA819643 & +7 & AMP protein kinase Prkaa2 & Fatty acid synthesis inhibition & 2 \\
\hline M19359 & +3.3 & Gamma-crystallin cluster & Chaperon protein & $\mathrm{B}$ \\
\hline X54510 & +2.1 & ATP synthase (ATP5i) & Respiration & $\mathrm{B}$ \\
\hline U50194 & +2.3 & Tripeptidylpeptidase 2 & Proteolysis & $\mathrm{B}$ \\
\hline AI170403 & +2 & proteasome associated protein & Proteolysis & $\mathrm{B}$ \\
\hline U77777 & +2 & Interferon gamma IL 18 & Proinflammatory response & $\mathrm{B}$ \\
\hline
\end{tabular}

Note. Negative and positive fold changes correspond respectively to down- and up-regulation of genes in RCS RPE. The GenBank accession numbers are listed for each gene. Genes are classified according to the function of their corresponding protein.

a Two different types of software were used for microarray analysis. 1, GeneChip Expression Analysis Window software; 2, Array Suite 5.0 software; B, genes common to the two programs. 
Table 2

Genes found to be modulated by both the GeneChip Expression Analysis Window and the Array Suite 5.0 programs

\begin{tabular}{llllll}
\hline GenBank & Change & Name & GenBank & Change & Name \\
\hline AA892801 & -8.1 & Elongation factor 2 & X76489 & -2.1 & CD9 glycoprotein \\
M21476 & -5.3 & Iodothyronine 5-monodeiodinase & AF106860 & -2 & GAPDH \\
X77934 & -4.5 & Aplp2 & AF041066 & -2 & Ribonuclease 4 \\
AA875069 & -3.6 & Histone H3 b & M93297 & -2 & Ornithine aminotransferase \\
A1008852 & -3.3 & Elongation factor 1 alpha & M27467 & -2 & Heart COX VIc \\
M74494 & -2.9 & Na+K+ATPase & AI012183 & 4 & Nrf2 \\
AA685903 & -2.9 & GRP94 & M81183 & 3.8 & IGF1 \\
AF122902 & -2.8 & beta actine & AI236721 & 3.6 & 14-3-3 \\
Z54212 & -2.6 & Emp1 & X05566 & 3.4 & Myosin regulatory light chain \\
M24852 & -2.6 & PEP19 & M19359 & 3.3 & Gamma-crystallin cluster \\
S81353 & -2.4 & Sulfated glycoprotein-1/saposine & AI233261 & 3.2 & Glutamate-cystein ligase (Gclm) \\
D84477 & -2.4 & RhoA & X59859 & 3 & Decorin \\
U03763 & -2.4 & Phospholipase A2 & AA926149 & 2.3 & Catalase \\
L13445 & -2.4 & Syalyltransferase 8 & S63521 & 2.3 & GRP78 \\
U88324 & -2.4 & Protein G beta 1 (Gnb1) & U50194 & 2.3 & Tripeptidylpeptidase 2 \\
U67995 & -2.4 & Steoaryl-CoA desaturase 2 & U15734 & 2.1 & Reticulocalbin 2 \\
U35774 & -2.2 & Bcat1 & X54510 & 2.1 & ATP synthase (ATP5j) \\
X89383 & -2.2 & SNF1 & U77777 & 2 & Interferon gamma IL 18 \\
AA924326 & -2.2 & Aldolase A & U10995 & 2 & Nr2f1 \\
X92097 & -2.1 & Coated vesicle rnp21.4 & AI170403 & 2 & Proteasome associated protein
\end{tabular}

Negative and positive fold changes correspond respectively to down- and up-regulation of genes in RCS RPE. The GenBank accession numbers are listed for each gene.

included in our results 19 transcripts for which the magnitude of modulation was between 1.5- and 2-fold (Table 3). The expression of 55 unknown sequences or ESTs was modulated according to the GeneChip Expression Analysis Window software compared to that of only 19 with the Array Suite 5.0 software. We performed sequence analysis with the BLAST software (www.ncbi.nlm.nih.gov/BLAST) to identify real unknown sequences and to remove sequences that were homologous to known and previously detected genes. This allowed us to identify 15 unknown sequences that were modulated in the RCS rat (Table 4). The expression of 8 of these transcripts decreased and that of 7 increased in the RCS RPE.

Oligonucleotides were synthesized for 12 of these genes ( 2 genes were the same as those found with DDRT-PCR) on the basis of sequences retrieved from the GenBank database (www.ncbi.nlm.nih.gov). These oligonucleotides were used for sqPCR.

Table 3

Some genes that are significantly up- or down-regulated (1.5- to 2-fold) in the 14-day-old RCS RPE compared to the congenic controls

\begin{tabular}{llll}
\hline Genbank & Name & Change & Function \\
\hline M64733 & TRPM-2 (clusterin) & -1.9 & Lipid metabolism \\
AB004277 & Protocadherin 5 & -1.6 & Cell-cell interaction \\
M15474 & Cypha-tropomyosin & -1.9 & Cytoskeleton \\
X52815 & Cytoplasmic-gamma isoform of actin & -1.7 & Vesicle trafficking \\
X74401 & Rab GDI beta & -1.9 & Cytoskeleton \\
M34043 & Thymosin beta-4 & -1.7 & Metabolism \\
D10706 & Ornithine decarboxylase antizyme & -1.8 & Metabolism \\
D16554 & Polyubiquitin & -1.7 & Metabolism \\
X54081 & Cytochrome c oxidase subunit IV & -1.7 & Glycolysis \\
X02610 & Non-neuronal enolase (NNE) & -1.6 & Lysosome \\
X54467 & Preprocathepsin D & -1.8 & Membrane protein \\
M11071 & MHC class I cell surface antigen & -1.7 & Trophic factor \\
J04488 & Prostaglandin D synthetase & -1.8 & Matrix \\
U75928 & SPARC & -1.9 & Cytoskeleton \\
X52840 & Smooth muscle myosin RLC-B & 1.9 & Lysosome \\
D90211 & Lysosomal glycoprotein LGP96 & 1.6 & Metabolism \\
M96601 & Taurine transporter & 1.7 & Metabolism \\
S68135 & GLUT1 (glucose transporter 1) & 1.6 & Oxydative stress \\
X07365 & Glutathione peroxidase 1 & 1.5 & \\
\hline
\end{tabular}

Note. Negative and positive fold changes correspond respectively to down- and up-regulation of genes in RCS RPE. 
Analysis of transcripts in the 21-day-old rat RPE

DDRT-PCR was used to identify changes in gene expression in the RPE of 21-day-old RCS dystrophic rats. We performed 300 duplicate DDRT-PCRs, involving 150 different combinations of oligonucleotide primers. Only a small number of consistent changes were observed when we compared dystrophic and control RPE RNAs. On average, about one change occurred for each primer set, allowing us to recover about 150 cDNAs. To identify true positive cDNA fragments, 104 cDNAs were screened using SSCP acrylamide gels. Only 30 of these cDNAs were unambiguously differentially expressed. These 30 cDNAs were excised from the gel, eluted, and cloned into the pGEM-T Easy vector.

Sequencing of these cDNAs revealed 23 different sequences, 6 of which were unknown and 17 of which were known. Oligonucleotides were synthesized on the basis of sequence data for 14 of these cDNA fragments (Table 5) and used to perform sqPCR.

\section{Study of unknown sequences}

Three unknown modulated cDNAs, the 1-12-4, 7-5-3, and 8-13-1 clones, were elongated resulting in, respectively, 1538-, 3873-, and 1037-bp fragments (Table 6). None of these sequences corresponded to any known cDNAs, although, the 1-12-4 and 7-5-3 clones corresponded to clones upon sequencing in the rat genome.

\section{Verification of differential expression}

To confirm the results of the microarrays and DDRTPCR, we performed sqPCR, using the cyclophilin $A$ or the Ribosomal protein $P 0$ gene as internal controls. These two genes are currently considered to be the most reliable internal controls and their expression is not modified in RPE cells during phagocytosis (data not shown). The most common control genes are GAPDH and actin, however their expressions increase during phagocytosis (Table 1). SqPCR was performed in duplicate with each control gene to test the reproducibility of each reaction. All bands corresponding to the gene of interest were quantified with the Scion Image software and normalized according to the controls. RNAs from 14- and 21-day-old rats were used for duplicate sqPCR, to study the changes in gene expression that occur even before and at the beginning of the retinal dystrophy in RCS rats.

SqPCR showed that the expression patterns of 11 of the 14 DDRT-PCR clones were modified. No significant modulations were observed for the LMW G-protein (Rab34) or for the ubiquitin-associated protease 1, even though there was a slight downward trend in both cases. Eight of 10 changes detected by the microarrays were confirmed by sqPCR. Some of these modulations are shown in Fig. 2 and the percentages of modulation after normalization are de- tailed for all genes in Table 7. The transcription of the CD9 gene, encoding a protein involved in cell-cell fusion, was without doubt modulated during the microarrays experiments but the result was not reproducible with the further sqPCR analysis. Finally, $80 \%$ of the genes detected in the RCS RPE using the microarray analysis were unambiguously modulated in the same direction in the sqPCR experiments. In most cases, we obtained the same general upward/downward trend for the Affymetrix microarray system and DDRT-PCR (Table 8). We used database mining to confirm the cellular localization of most of the known transcripts found to be expressed in control RPE cells by the microarray analysis. This validated our specific microdissection method and of course the specificity and the quality of our mRNAs. Our microdissection method was further validated by the fact that archetypic proteins, such as GRASP55 and Paxillin-Linker-Protein, extracted simultaneously from RCS and control RPE cells microdissected according to the same method applied previously, could be detected by Western blot and immunohistochemistry (Fig. 3).

\section{Discussion}

The goals of this study were to identify genes involved in outer segment phagocytosis in the normal RPE as well as to characterize modulations of gene expression in RPE cells associated with the phagocytic dysfunction and with changes in RPE cell metabolism of RCS rats. We compared the RCS RPE with that of its congenic strain, which differs only by a deletion in the c-mer gene. To examine the effect of the lack of phagocytosis on RPE metabolism, we used microarrays in 2-week-old rats and RT-PCR differential display in 3-week-old rats. Neither of these techniques can screen $100 \%$ of the expressed and/or modulated genes. These two techniques are based on different, but complementary, principles. The microarray approach allowed us to examine the expression profiles of over 8000 genes or ESTs but could not find novel sequences. Conversely, DDRTPCR, with its arbitrary primers, is more flexible and can be used to identify new coding sequences. The results obtained by each method were verified by sqPCR at both ages. Two different computer programs were used to analyze the microarray results. A reproducible two-fold difference in expression levels was deemed significant by the manufacturer following extensive testing of their procedure prior to its commercialization, with $\leq 1 \%$ false positives. Thus, the modulated genes identified by both techniques are the most significant. Some of the results obtained differed, but this apparent mismatch can be explained by the highly selective nature of the results: we used two criteria with both programs: high statistical relevance and fold change $(>2)$. Few of the genes appeared to be common to both analyses, but more genes were modulated by both methods when lessselective criteria were used. Genes found by one of the two 
Table 4

Accession numbers and fold change of unknown modulated EST found with the microarray analysis

\begin{tabular}{llll}
\hline Probe set name & Fold change & Probe set name & Fold change \\
\hline rc_AA875327 & -2.5 & rc_AA799537 & 5.0 \\
rc_AI103396 & -2.4 & rc_AA894009 & 4.2 \\
rc_AA963674 & -2.3 & rc_AA800930 & 3.4 \\
rc_AA858570 & -2.2 & rc_AA892759 & 2.6 \\
rc_AA859372 & -2.1 & rc_AA875059 & 2.5 \\
rc_AI639076 & -2.1 & rc_AA874873 & 2 \\
rc_AA893485 & -2 & rc_AI639042 & 2 \\
rc_AI639510 & -2 & &
\end{tabular}

Note. Negative and positive fold changes correspond respectively to down- and up-regulation of genes in RCS RPE.

softwares analyses are also relevant, as sqPCR confirmed the results provided by each of them. Microarrays permitted us to determine 125 modulated genes in the RCS RPE. After categorization, $33 \%$ of the genes found to be down-regulated in the RCS rat appeared to be related to phagocytosis and phagosome composition. These genes correspond more specifically to the absence of shed outer segment engulfment. Another $45 \%$ of the down-regulated transcripts were found to be related to a decrease in general metabolism (glycolysis, lipids, and proteins), which is in accordance with the decreased activity of the mutant RCS RPE. The results of the microarrays were also validated by sqPCR and DDRT-PCR. Even though the PCR technique is less sensitive than the microarray technique and is condition dependent, the sqPCR results confirmed most of the microarray results in 2-week-old rats. DDRT-PCR provided us less information than the microarray method, because it is PCR based and produces cDNA bands that are not frequently immediately unique and may require several rounds of further purifications. However, this method allowed us to find six unknown RPE-specific sequences. SqPCR confirmed that the levels of four of these cDNA sequences were indeed modified by the RCS homozygous deletion. Three cDNA fragments were successfully elongated and gave us three sequences of 1-, 1.5-, and 3.8-kb long (Table 6). Further studies on the full-length cDNAs and their corresponding novel genes as well as the genes encoding modulated ESTs (Table 4) are currently underway and should provide additional information on the phagocytosis of POS specifically and apoptotic bodies more generally. The mechanisms underlying phagocytosis are exceedingly complex (Aderem and Underhill, 1999; Greenberg and Grinstein, 2002; Underhill and Ozinsky, 2002). Some general principles can be discerned in the phagocytic processes. (1) Phagocytic receptors recognize specific ligands on target particle/cell. (2) These receptors trigger intracellular signals that direct polymerization and the rearrangement of filamentous actin and coordinate the tractional forces that internalize apoptotic bodies. (3) Membrane trafficking is required to compensate for the membrane lost at the cell surface and to modify the membranes surrounding the vacuoles in the maturing phagosome.

Three major findings emerge from this work: (1) Specific tyrosine kinase signaling pathways, such as the DLK MAP kinase, JNK/SAPK, PI3-K, Akt, and mTOR signaling pathways, are altered. These signaling pathways could be critical in the normal signaling pathways of the c-mer tyrosine kinase receptor. (2) Endoplasmic reticulum (ER) proteins, which have been involved so far exclusively in an in vitro model of phagocytosis (Gagnon et al., 2002), are demonstrated to be implicated for the first time in an in vivo physiological phagocytic process: the phagocytosis of POS by RPE cells. (3) The decreased phagocytosis of POS in RCS rat RPE is associated with decreased endomembranes biosynthesis, altered phagosome formation, decreased exocytic and endocytic processes, decreased vesicular trafficking, decreased cytoskeleton rearrangements, and decreased biosynthetic and catabolic activities (respiration, glycolysis, and lipids).

The absence of a functional c-mer tyrosine kinase receptor in RCS RPE cells is expected to have a major impact on the signaling pathways that are activated during POS phagocytosis. Phagocytosis involves the active assembly of actin microfilaments, and it is thought that the MAPK kinases play a role in this process. Indeed, the microarray analysis allowed us to detect a significant down-regulation of the the Dual Leucine Zipper-bearing Kinase (DLK) gene expression, also called Mitogen-Activated Protein Kinase Kinase Kinase 12 (MAP3K12) in RCS RPE cells. Many protein tyrosine kinase receptors and their signaling pathways are often clustered in the vectorial subcellular domains determined by caveolae (Razani and Lisanti, 2001; Anderson and Jacobson, 2002). Importantly, caveolae contain all of the essential components required for MAP kinase activation (Waterman and Yarden, 2001). The DLK gene, also called MAP3K12, belongs to the mixed lineage kinase family

Table 5

Genes corresponding to the cDNAs cloned with the Differential Display method

\begin{tabular}{lll}
\hline GenBank & Name & $\begin{array}{l}\text { Trend in } \\
\text { RCS RPE }\end{array}$ \\
\hline NM_021340 & G protein-coupled receptor RGR opsin & Decrease \\
NM_010024 & Tyrosine-related protein 2 Tyrp2 & Decrease \\
NM_031179 & Splicing factor 3B & Decrease \\
X16262 & Myosin heavy chain 11 Myh11 & Decrease \\
NM_019299 & Clathrin heavy chain & Decrease \\
S72304 & LMW G-protein/Rab 34 & Decrease \\
Y17323 & CDK109 & Decrease \\
NM_011595 & Metalloproteinases inhibitor TIMP3 & Decrease \\
X70496 & Mss4 protein/Rab interacting factor & Decrease \\
NM_011909 & Ubiquitin associated protease 1 & Decrease \\
/ & Unknown clone 1-12-4 & Decrease \\
/ & Unknown clone 7-5-3 & Decrease \\
/ & Unknown clone 7-17-2 & Decrease \\
/ & Unknown clone 8-13-1 & Increase \\
\hline
\end{tabular}

Note. Accession numbers are given for known genes. 
Table 6

Sequences of the unknown cDNAs that were elongated from Differential Display clones

Clone 1-2-4 (1538 bp)

GCTTGGCATGGTGGCACACATCTTTAATCCGAGCACTCGGGAGTCAGAAACAAGCACATTTCTGTGAGTTCAAGGCCAGCCTGGTTTACGTAGTGAGTTTCAGGTCA GTAAGGACTATATAGTGGGACTATGTCTCAAAATAAAAATAAAAACTGCACTGTACCTTAATTTTTTTTGAGACAGATTCTCATGTATCCCAAGCTGGCATTTAAAC TCACGACATAGCTGAGAATGACCTTGAACTTTTTTTTTTAAGATTTATTATATATGAGTACACTATTGCTGTCTTCAAACACAGCAGAAGAGGGCATCAGATCCCAT TACAGATGGTTGTGAGCCACCATATGGTTGCTGGGAATTGAACTCAGGACCTCTGGGAGAGCAGCCAATGCTCTTAACCAATGAGCCATCTCTCCAGGCCGACCTTG AACTTCTGATGCGCCCAACTCTGCCTCCTGAGTGCTGGGACTACAGGTGTGAACCACTGAGCCTGGTTTGCTTTATTAGAGATTAAATCAAAGATTTCCTCCATTGT CAGCAGCATGTCTGCCAGCCTCGCCACAGAGCCAACGCTGTACTGTGCATCTAAATGGACTAATTGTAACATCCACGAATTACACATCAATAGGCTGTCATTTTTAG AGGAGGGAGAGTTGGGGTTTTCTTGGGGGGGTCATTTTTTGTTTGTTTTTTGTTTGTTTTTTCTTTTCTTTCTTTCGTTTTTTTTTTTTTTTTTTTTTTTGAAACAA GATTTCTGTGTGGCCCTGGCTGTCCCGGAACTCACTGATCTGATCCAGGGAAGACTGTGCTTCCTACGAATCCCTAGTCTGGGCCTGAGGGGGCAAAACCCTCTCTA ATTGTGGGTCTGTCTGCAGCGCTCAGCCCTCTCATCTCTCTTAGCTGTGGGGAAGGTCTATGCAGCCACTGCCCAGCTCCCAGGTTCAAATCTCAGCTCCACTACCT AACCAGCTCTGTGACCTCAAAGAACCCCTACTCTCGCTGAGCCTTGGCCTGACAGTAACTAACACCCGACACTAGGGTCCCTGTGTGTCAAACTCAAGCTGATTTCA CGGAGCCCAGTGAGTTCATGTAACACTCACCATTGAGCTATAGAGGCAGAAAGAGAATCTCGGGGCTAGGGTACAGGGGCTTCCCTAGCTTCCCTGTGTGACGCTAT GGGATCCATTCTTAGCAGAGAGAGGAGGGAGAGGAGAAGGGAAGAAGGGAAGAGGGAGAGAGAGGGGAGAAATGCTTACTTAGACTATAAAAGTCTTGCTCAGAAGC TGAGGCGTCACTAGGAACCTGTCTTATTGGCTGTGATTTGATGCCAAGACTCAGCGAGCCCACAATGCACCGGGTCTGGCTGAGCCTGCAATGTACAGTTGGGCTGT GTTTTGTTGCTCTGTTTTGTTTTCTTCTTTTTTTTTCTTTTTCTTTTTTCTTTTTTTTTCGGAGCTGGGGACCGAAAAAAAGAACTTCATTTTAGAAAAAAAACA GAAGGAAAAAAATTGAACTCTGCGTTGTTACCACTGCTTA

Clone 7-5-3 (3873 bp)

GGAGGATCTGGGTGCATGTCTGCTGCAGTCGGCCTGTGTGCTCCAGGAAGGAAAGTCCCCACGGCAGTGCTTGAAGGAAGGCAACTGTAGAGCTTTGCAGTACTCGT TTTTTGAGTGTAAGAGATCAATGTTGGATGCCAGATCAAGATTCAGAGGAAGAAAAGGATATTGATAATGTCATGTTGGACGAAGATGAAAACCACTCAGAATTTTC TCTGGTCCTTAACAGAAAAGAATCAAAGTAGGAAGCACAGTAGCTGCCACATCTGTTCAACCTCTGGGCCTCCCAAGTACACCAGAGAAAACAGATCAATGCTGTTT CTGAATGATTCTGCTGGTTAAAGTCATTTATAGAAGATTCACGATACTGAACAACTATGGGTTAAGAACTTACTGTGTTTTGTGAATTGCCCAATGGAGAGAGTGTG TTCAAGGATGACTCTTGATCAGATTACACAGTATGTGCATCCAGGAGGCCACATGAAATCAGCATAGTTAGTAACATAGAATCTGTTGTCAGCCTCCTCCAACTCGT GTCTGTTTCTTGGTTTCAATTTTAGGCCAGCCCTCTCCTCATAAAGGGGTGATAGTAGCCACAGTCCACAGCCTCAAGGTCTGGTCTCCAAAAAGAAGAGTGTGAGC TGGGCCACAATCATACCCTCCTGAAGAACTCTGGTCTTTTCTGGTCATATGCTCCTGCCCCACCCTTGGTGATCCTGGCTAGATCATGGTCTTCCCGTACTGTGCCG ACACCATTCACAGTAACATAGGATGAGTTATGGGCCTCATCCCTAAACACTGGAACTTGCAGCAAATGATGTAGCAGATATTCACTCTAGATAACAAATGTCAGTGA CATGAAGTGGCTAGGAAAGTTTAGAACCCTGATCATTTTATTTTTACCACTTAACACAGTAGAGAGCCATCAGGACTAAATCTTTGGTGTGATTCTTGCCATTGAAG TCATTATAGCTTCCATATTGTTCCGTAGTTCACTGGAAAGTGCACTTGCTGTTAAAAGTTTTGAAGCTGTGAGGATTCCCTAGGGTGTCACTGAAGTCTGCTCTGTA TACTGCCCCCACTGGGAGTGCACGGTACTGCACCCTTAAATCCTGCCGCCTGTGTCCCAAACATGGTGTCTGCGTGCAGTGTGGAGTAGTGCGCCCTCCTTTTTTTT

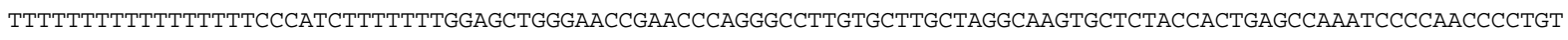
AGTGCGCCTTCTATACTAGAAAGCTTGACCACTGAGCCACACCTCCCACTAGTGCTTCAATGTCAACCGAGAGTAAAATGTGTTTGTATGAAATGCCTCCATTTGAC TAGATAGAGCTTTATTTGGAGAAAGTCACATATAACATAATTGAACTTTGAATTATACAATCCCGTGGATTTTAGAGTGCTCCTGGAGCAGGTGGCAGTCACCACTA TCTACTTCCAGAACAGTCTCATCCTTTCCAGAAACCCACACTCTGTCTTTCCTCTATTCCAGATCTGTTAGACGAGTGGAATTACATAGTCCGGTCTTTTCTGAGTT CTGTTACTAAGTTTTAAAGGTTTATTCTCAGGTAGCATCAGTCCGTAATGTATTACTGCTGAATAGTGTTCCGTGTATACAGACACCGTGTGTGTCTTCTTCCAGCG AGCAGAGGAACTCTGAGCTGTTTCTACTTTGGGGCTTTTGACTAATGCTATGAACATCTGTGAAAAAGTTCGAAATGTTTGATtTAGTACAGACCCTAGTGGGGAGC TCCGGGGTCATATTATGACAGCCTCAATTGTACTTCCTACAGTGGTTTTACCACCATTTCCTGCTCTCGTGGGATCTAGGCTCCAGCATCCCTCACAACTTTCTGCC TGAGATGAAGAGGCATCTGATTGGGATCTTGGTTTGCATTTCCCTAATGTCTAATAATCTGAGCTTTTTTTCATGTGTTCATTGGCTTTCTATGCTGCTTTGCAGAA TGTTTATTTCAGGCTACAGTCTGCCTTTCAGCTGGGTTATCTTTCTGTTTTTCTGTAGGATTTTTTATTTACGGTCAACTCATCTCTTAAAGATTAATTGGCATTTT TTTTTTCTCAACTTGTGGTTTGCCCTTCTCAATGTCTTGATGCTCTCTGAAGCACAGTTTTTATTTTTATATATTGCCTTTCTGCGTCTTAGCCCAGGCTGGCCAGG AATCCCCAAAGCCTTGTACACAGAGTGAGCATTTTCACCGCCTCACTTCCCAGAAGGCACACGGCGCTGCTCCTGCCTAGAGCAGTTTTCATATTGGAAAATAACAA TGTGTTTTTTCTTTCAGTGTATCCTAAGAAACCATTCCTAACCTGGACTTACAGAAGCCTATGTCTTCACTAAAGAATTTTTAAATTTTACCTCTTACCTGTAGGCC TGTGCTCTCAAAATGTTACACACCTTTATTCATGGCCATATTTAAAATTAAGTAGAAATAGTGAGTATGTAGATATGCCTGTATCGTGATGAGCACATTCACAGTGC AGTGCAGTTGGCCTGCAGCCCAGTTCTGCATCCACCTCAGAAAATGCCCAGTGAGCCCATCTAATGACTCCCAGCCCCTGCCAGGTCCTCCCTCCCTGCCCTGTCTT GGCATACTCTCTCTCCATGGCAATCACCATTCTCTGTCCTGTTTCTGAATTTGAGTACCCTAAGTGCCTGGTATACATAGATTCTCAGTGCGTGTGTGTGTGTGTGT GTGTGTGTGTGTGTGTGCGTGCGTGTTCATGTAGCAGAATGCCGTGAAGGCTTGTATCATGTATGAGTTTCCTTTGTAAGGACAAATAGTACTTTAGACTTTAGTGT GTGTTGTATGTATGCTGTATGTTTCTTGTTACCTACTCATCCAGCCGTGGGTACCTCAGTTGTTCCCACCCTGGAGCTCCTGACTATGCTGTGAACATGTATATACA AATATCCCTCGGATCCTGCTTAGCATACACGCAGCAGATTGTATGTCTTAGGGTAACTCTGCTGTTATTAGTAGGCACTGCCGTAGTCTCCATAGTGACCACACTAT TGTATGTCCTGGCAGCAGTGCACAGAGATTAGAAGTGCCCATGTCCTTGTGAGTCTTACTCTTTTTTAGTGGCTGTTCTAGTAGGTGTTAAGATCTGCTAGTGCTTC TGCTTCCCATCTCTCTGACTACTGATGTCACATGTTTTATATGCTTGGTGGCCTTCTTTATATATCGTTTGAAGAAATCTCTTTAGGTCCACTGTCCATTAATAGTT GGGTCGTTGGCTCTGGTTGAATTTTTGGTAGTCACATCCACAAAAGCATTAACCCACCCAAGGGAGCCTACTACAGCTTGCCCTAGGAAACTTGATTTTAGCTCTTA GCTTTGCTCTCTGGTATATTTTGAGTTCATTTGTGTGTGAGATGTAAGGTCTGACTTTCTACTCTACCCATGTGGATACCTGGCTTTGCATGTTGCCCTTGGTGGGA AAACATCCCGCTGTGCATGGTGGGGCTGTTTCTGAGCCTGGTCTCTTCCATGACCTCTGTCTGCCTTCATGCCAACGCCACTGCTTTGATTACTGGAGAATTATAAT AGAAATTTGAAATCAGAAAATGTTTGTTCTGTAATAAAAATTTGAAATCAGAAAGTGTTCTATAATAAAAATTTGAAATCAAAAAAAAAAAAAAAAAAAAAAAAAAA AAGTACTCTGCGTTGTTACCACTGCTTGCCCTATAGTGAGTCGTATTAGAATCGAATTCCCGCGGCCGCCATGGCGGCCGGGAGCATGCGACGTCGGGCCCAATTCG CCCTATAGTGAGTCGTATTAC

Clone 8-13-1 (1037 bp)

GAGGTGGAAACATTGAACTAGAAGATCATAGAACAACTTTACCTACAGTTGTAAAAGGAGCGATTGCGTAGCTATTCTCTCTGGGTTAGGCATGATGACTGCCATTT TGAATCACCACATGAGACCCGCAGGAGACCAGACCTAGCTGATAGAGCCTCATGGTGGAAAGGTGTTCCTCTCACAGGGAAGAACTCTGCTTCCTGCCATGGTCTTA TAGCATCTGGGCCAGCCAGGTTAATGCCGCAACCTGGCCTTTGTGAGAGAATCTGTTTATGGCAAAGAGACGTGATTAATGAGGAACACACATATGATGGTGGCATG CTCCGCCCTACATGGGACCACTATATCATCCCCATCAAGGACCAGAGAACATCATCCAGGAGAAGGCAGGAAGAACACAGAAGCCAGAGGAAGAGGTCTAGCTAGAA GATGTCTTCTGCACTCAAGAACTAACTGAAGTTGCGGTATCTGAACAAGACTGCCAGGAGACAGGGTCCAATACCCTTTCTTCAGGGTTGTGGGAGGGACTCATAAG GGTCCTCCTCTTCCTGAAGGGCAGGCGGAAGCTAATGGTTGCCAGGAGACATGGAGGTCGCTTTTGTCAGTGGTGTGACTGCTGAGAAGATCCCTGGCTCCAGTAAA GGTCCCACCCACATAGAGCTCTAATGAAACTCAGTGGGTCACCCACAAAGGCAAGAGACAGGAGCACTTGATAGAATATGGGTTTCAGTAGGAAAGGAGTGGAAGTG ACACGGGAGAATGGGAGGTTTAAAAACGACTGAACCTCACTGTAGAAAAGTGTGAAGTTATCAAACGACAGCAACAGAACGTGTCCACGAGGAAATGGCAAGACCCA GACAGCCTTCTGTTTAAAAGAGATATATTCTTTACCATTCAAGCATCTCTGTGTTTTAAGAAATCTCCATAAATAACTTTCTCAAGTTGCTTTTTAAATAAAGATTA CCCAGCAAAAAAAAAAAAAAAAAAAAAAAGTACTCTGCGTGTTACACTGCTTGCCCTATAGTGAGTCGTATTAG 
$\mathbf{A}$

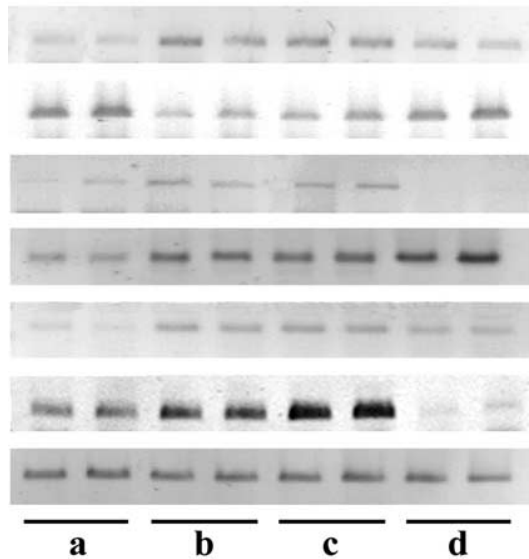

TTR

PEP19

TFR B

RGRopsin

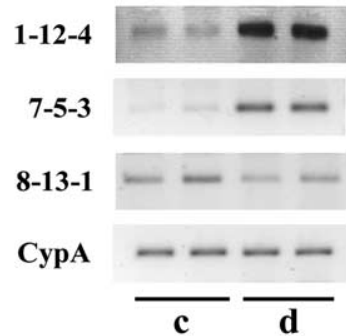

Fig. 2. Example of duplicate semiquantitative RT-PCR for known genes (A) and unknown cDNAs (B). (a and c) RCS RPE, (b and d) control RPE; mRNAs from ( $\mathrm{a}$ and b) 14-day-old and (c and d) 21-day-old rats. CypA (cyclophilin A) is the internal PCR control. TTR, transthyretin; TFR, transferrin; RGR opsin, G protein-coupled receptor; Timp3, tissue inhibitor of metalloproteinase 3.

(MLK) (Ikeda et al., 2001). DLK activates the c-Jun NH2 terminal kinase (JNK)/stress-activated protein kinase (SAPK) pathway through MKK7 (MAP kinase kinase 7) in cells (Nihalani et al., 2001). DLK mediates JNK activation in neuronal apoptosis. AKT is an intermediate between tyrosine kinase receptors and JNK. The absence of the c-mer receptor probably diminishes AKT activation and is likely to decrease the activation of the JNK/SAPK signaling death pathway significantly. Thus, the down-regulation of DLK gene expression might counteract JNK-dependent death mechanisms and delay RCS RPE cell death. Interestingly, the microarray analysis shows that the mammalian Target Of Rapamycine (mTOR) gene is down-regulated in the RCS versus rdy RPE cells. After the stimulation of the insulin receptor or other growth factor receptors such as c-mer, PI3-K activates AKT, which in turn activates mTOR. This leads to increased rates of protein synthesis and ultimately results in increased cell size (Inoki et al., 2002; Gao et al., 2002). The mTOR pathway is influenced by the intracellular concentration of ATP, independently of the abundance of amino acids, and mTOR itself is an ATP sensor (Dennis et al., 2001). Moreover, western blot results (data not shown) suggest an associated decrease of the mTOR protein levels in the RCS RPE cells. The reduced transcription and translation of mTOR may be associated with the global reduction in metabolic activities induced by the abrogation of POS phagocytosis and the subsequent reduction in endomembrane biosynthesis in RCS RPE cells.

During the normal phagocytosis of the shed photoreceptor outer segments, the POS bind to receptors on the surface

Table 7

Quantification by semiquantitative RT-PCR of the genes detected by both methods

\begin{tabular}{|c|c|c|c|c|c|}
\hline \multicolumn{3}{|c|}{ Differential display modulations } & \multicolumn{3}{|c|}{ Microarray modulations } \\
\hline & $\begin{array}{l}\text { RCS vs Rdy } \\
\text { 14-day-old (\%) }\end{array}$ & $\begin{array}{l}\text { RCS vs Rdy } \\
21 \text {-day-old }(\%)\end{array}$ & & $\begin{array}{l}\text { RCS vs Rdy } \\
14 \text {-day-old }(\%)\end{array}$ & $\begin{array}{l}\text { RCS vs Rdy } \\
21 \text {-day-old }(\%)\end{array}$ \\
\hline RGRopsin & -20 & -20 & CRBP & -33 & $\mathrm{NC}$ \\
\hline Tyrp2 & -50 & $\mathrm{NC}$ & Cystatin C & -25 & -5 \\
\hline Splicing Factor3 & $\mathrm{NC}$ & -70 & Dri27/ZnT4 & -10 & +10 \\
\hline Myosin Myh11 & $\mathrm{NC}$ & -10 & PEP19 (pcp4) & +40 & -20 \\
\hline Clathrin Heavy & -10 & -10 & prosaposin & -25 & -5 \\
\hline Unknown 1-12-4 & $\mathrm{NC}$ & -15 & Transferrin & -25 & +33 \\
\hline Unknown 7-5-3 & $\mathrm{NC}$ & -70 & Transthyretin & -40 & +15 \\
\hline Unknown 7-17-2 & -15 & -5 & ApoE & -50 & +450 \\
\hline Unknown 8-13-1 & -15 & +33 & EST AA892759 & +5 & +35 \\
\hline \multicolumn{6}{|c|}{ Genes modulated in both techniques } \\
\hline CDK109 & -25 & -5 & Timp3 & -25 & +10 \\
\hline
\end{tabular}

Note. Reactions were carried out using RPE mRNAs from 14- and 21-day-old RCS and control rats. Results are expressed as a decreased or an increased percentage of the PCR products in the RCS RPE. NC, no change. 
Table 8

Summary of the common results obtained with both methods

\begin{tabular}{lc}
\hline Microarrays & DDRT-PCR/SSCP \\
\hline 8801 oligonucleotides tested: & DDRT-PCR on RCS/control samples: \\
5373 known genes & 150 primer combinations tested \\
3428 ESTs & 150 cDNAs extracted \\
In normal RPE: & SSCP: \\
3700 sequences present & 104 cDNAs tested \\
5101 sequences absent & 30 cDNAs modulated \\
Comparison RCS/control & 30 cDNAs modulated: \\
RPE: & 17 known genes \\
125 sequences modulated & 6 unknown genes \\
(fold $>$ 2) i.e., 110 & 7 redondant sequences \\
known genes & \\
15 unknown genes & \\
Common cDNAs between the two techniques \\
CDK109-Timp3 \\
cDNAs detected by one technique and confirmed by sqPCR \\
Microarrays: 9 cDNAs among those tested (see Table 7) \\
DDRT-PCR: 9 different cDNAs among the 30 sorted after SSCP (see \\
Table 7) \\
Further analyses: sqPCR \\
24 sequences tested, 12 \\
from each technique: \\
20 displayed expected \\
modulation \\
3 displayed no difference \\
1 displayed an opposite \\
modulation & $(12.5)$ \\
\hline
\end{tabular}

Note. Values in parentheses are percentages.

of the RPE cells, triggering the extension of pseudopodia and resulting in an actin-based movement of the cell surface. The pseudopodia eventually surround the shedding POS and their membranes fuse to form the large intracel- lular vesicle, called a phagosome. The functional properties of phagosomes are acquired through a complex remodeling process involving regulated interactions with a series of endovacuolar organelles. Indeed, during phagolysosome biogenesis, phagosomes intersect the biosynthesis pathway and fuse sequentially with early endosomes, late endosomes, and lysosomes. Receptors that mediate the phagocytic uptake include scavenger receptors, integrins, lectins, and, importantly, protein complexes that are usually found in the ER (Henson et al., 2001). Several receptors, transport, and signaling molecules are likely to participate to the multistep process of POS phagocytosis by RPE cells. The collectin MARCO receptor expression is eventually downregulated (data not shown), whereas ApoE gene expression (Fig. 2, Table 7) and ApoE protein (Fig. 4) are up-regulated in 21-day postnatal RPE cells of RCS versus rdy rats. The microarray and proteomic analysis allowed us to detect decreased expression of genes corresponding to proteins known to be associated with the phagosome proteome of macrophages (Table 1). The V-ATPase gene encodes a proton channel implicated in the acidification of phagosomes, which may play a role in vesicle fusion (Strasser et al., 1999). We also detected the increased expression of genes corresponding to proteins of the phagosome in macrophages: lysosomal protein 96 (LAMP2), GRP78, and 143-3 kinase (Garin et al., 2001). These differential modulations may correspond to different stages of phagosome maturation. Our analysis showed that the expression of genes encoding lysosomal proteins possibly playing a role in phagosome maturation was modulated: the ATP6b2 transporter, which contributes to the acidification of lysosomes, prosaposin (Zhao and Morales, 2000), phospholipase A2 (Fischer et al., 2001; Ito et al., 2002), and cystatin C (Wasselius et al., 2001). In macrophages, part of the
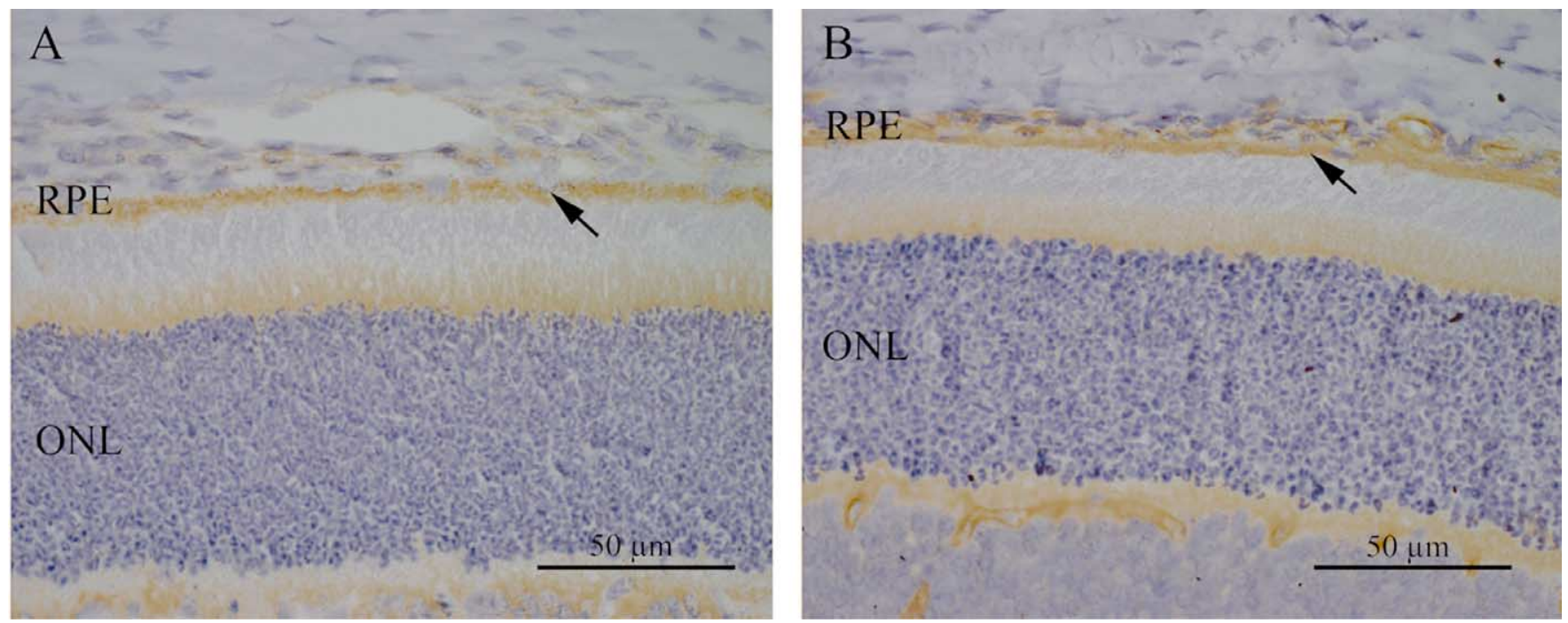

Fig. 3. Immunohistochemistry using monoclonal antibodies directed against Grasp55 (A) and Paxillin-kinase linker (B) proteins. Both proteins are present in the RPE (arrows), confirming the specificity of the dissection. RPE, retinal pigment epithelium; ONL, outer nuclear layer. Bar represents $50 \mu \mathrm{m}$. 

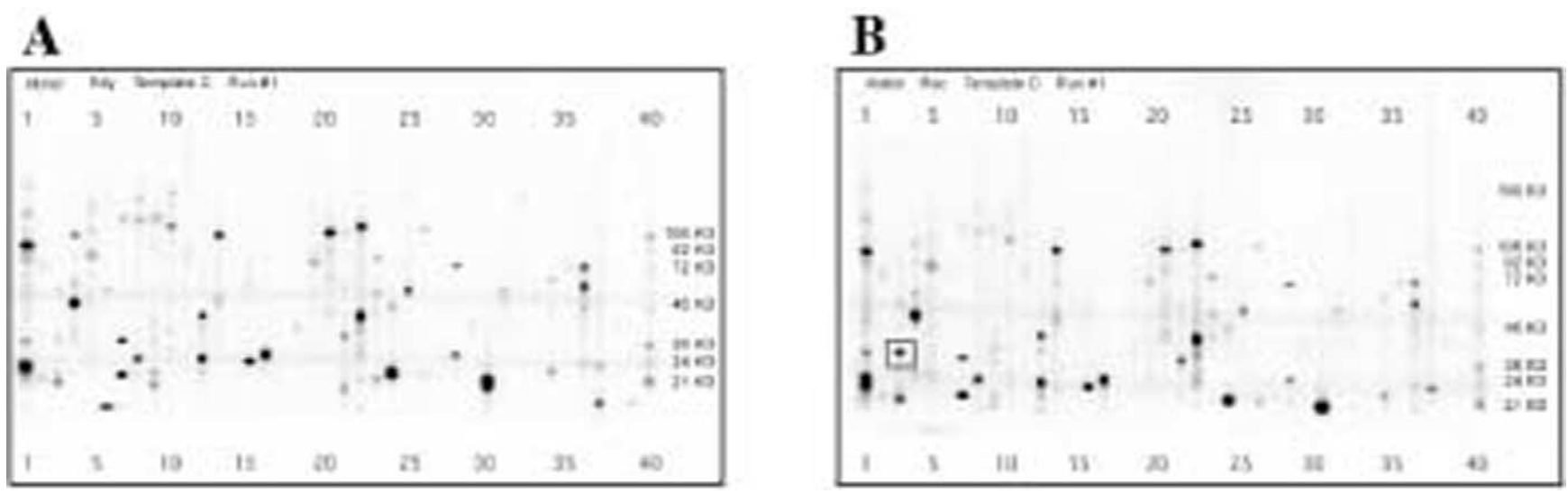

Fig. 4. Panel A shows the robotized mega Western Blot or PowerBlot corresponding to the immunoblots of proteins extracted at postnatal day 21 from microdissected RCS p+ rdy+ (i.e. rdy-control) RPE cells. Panel B shows the robotized mega Western Blot or PowerBlot corresponding to the immunoblots of proteins extracted at postnatal day 21 from RCS p+ rdy-(i.e. RCS) RPE cells. The ApoE immunoblot signal is dramatically increased at this stage with the proteins extracted from RCS RPE cells in panel B as compared to the ApoE signal observed with proteins extracted from rdy RPE cells, which is merely detectable in panel A. A square surrounds the significant ApoE immunoblot signal in panel B. All of the PowerBlot signals have been triplicated. It is worthwhile to mention that the semi-quantitative RT-PCR at the same stage (P21) provides highly compatible results. Picture from the PowerBlot showing the up-regulation of ApoE in RPE of 3-week-old RCS rats (PowerBlot System from Beckton Dickinson Company, Transduction Laboratory, Lexington, KY).

phagosomal membrane is derived from the ER (Gagnon et al., 2002). We found that the expression of a number of genes encoding specific ER proteins was altered (Table 1), confirming that ER proteins may be involved not only in one form but probably in several types of phagocytic processes, if not all. The phagosome proteome of macrophages (Garin et al., 2001) clearly showed that Rab and Rab regulatory proteins play a structural role in the phagosome. Rab proteins form the largest branch of the Ras superfamily of GTPases. They are localized to the cytoplasmic side of the organelles and vesicles involved in the biosynthesis/secretory and endocytic pathways of eukaryotic cells (Darchen and Goud, 2000). The DDRT-PCR analysis detected the down-regulation of the rat Rab34 gene expression, which is homologous to the human Rab39. The microarray analysis also detected the down-regulation of the beta rab GDPDissociation Inhibitor (GDI) gene expression as well as a decreased RhoA GTPase transcription. Perturbations of the interactions between GDI and Rab proteins could indeed affect phagocytosis, endocytosis, and exocytosis (Perskvist et al., 2002; Mallard et al., 2002). RhoA GTPase is a crucial molecule located at the crossroads of the endocytic and exocytic pathways and phagocytic processes (Frantz et al., 2002; Bruns and Jahn, 2002). The decrease of RhoA GTPAse gene expression probably reflects the general decrease of vesicular trafficking in RCS RPE cells. The microarray analysis detected a decreased transcription of the clathrin light chain A1 and A2 genes, whereas the DDRTPCR analysis detected a down-regulation of the clathrin heavy chain gene in RCS RPE cells. These results indicate that key molecules from the clathrin-coated vesicle endocytic pathway are significantly affected by the abrogation of ROS phagocytosis in RCS RPE cells. Several proteins implicated in vesicle trafficking have been also localized to caveolar fractions (Schnitzer et al., 1996; Puri et al., 2001;
Feng et al., 2001). As a result of its cholesterol-binding activity (Uittenbogaard and Smart, 2000), caveolin-1 is thought to play a central role in the formation of plasmalemmal caveolae. Western blots indicate that caveolin-1 levels are decreased in 21-postnatal-day RCS RPE cells (data not shown). These results strongly suggest that both clathrin-dependent and clathrin-independent endocytic pathways are affected in RCS RPE cells. Contractility involving actins, myosins, and diverse motor molecules is a major feature of phagocytic processes (Swanson et al., 1999). Rearrangements of the cytoplasmic cytoskeleton accompany the formation of phagocytic cups during the phagocytosis of the POS shed by normal RPE cells. They also accompany endocytic and exocytic processes. The DDRT-PCR technique and the microarray analysis revealed that several genes encoding proteins of the cytoplasmic cytoskeleton were down-regulated (Table 1).

\section{Conclusion}

This study enabled us to unravel signaling pathways altered by the abrogation of POS in RCS RPE cells, to show for the first time the implication of ER proteins in a physiological process of phagocytosis, and to emphasize the multiple cross-talks between phagocytosis, endocytosis, and exocytosis in RPE cells and very likely in cells of the monocytic lineage. The major conclusion to draw from this report is that, while most investigators working in the field of retinal diseases considered until now lipid metabolism as essentially important for POS renewal and photoreceptor cells in general, the RCS retinal dystrophy rat model reminds us strongly that lipid metabolism should be investigated more intensively not only for elucidating the pathophysiology of age-related macular degenerations but also 
for improving our basic knowledge concerning phagocytosis, apoptosis, cell adhesion, and the pathophysiology of immune deficiencies and cancers.

\section{Acknowledgments}

We thank Retina-France for their permanent financial and moral support. We thank Fiona Brewer from Affymetrix for her invaluable advice concerning the interpretation of our data. M.A. received grants from Ministère de La Recherche, Faculté de Médecine Necker, Université René Descartes, INSERM, CNRS, GIS PRION, Fondation de l'Avenir pour la Recherche Médicale Appliquée, Fondation pour la Recherche Médicale, Fondation de France, Association Française contre les Myopathies. E.M.D. is the recipient of a Retina France and of a Fédération des Aveugles de France PhD grants. E.N. is a recipient of a Retina-France and a Fondation pour la Recherche Médicale $\mathrm{PhD}$ grants. L.V.D.B. is a recipient of postdoctoral grants from Fondation de France and Retina-France.

\section{References}

Aderem, A., Underhill, D.M., 1999. Mechanisms of phagocytosis in macrophages. Annu. Rev. Immunol. 17, 593-623.

Anderson, R.G., Jacobson, K.A., 2002. Role for lipid shells in targeting proteins to caveolae, rafts, and other lipid domains. Science 296, 1821-1825.

Bok, D., Hall, M.O., 1971. The role of the pigment epithelium in the etiology of inherited retinal dystrophy in the rat. J. Cell Biol. 49, 664-682.

Bourne, M.C., Campbell, D.A., Tansley, K., 1938. Hereditary degeneration of rat retina. Br. J. Ophthalmol. 22, 613-623.

Bruns, D., Jahn, R., 2002. Molecular determinants of exocytosis. Pflugers Arch. 443, 333-338.

Darchen, F., Goud, B., 2000. Multiple aspects of Rab protein action in the secretory pathway: focus on Rab3 and Rab6. Biochimie 82, 375-384.

D'Cruz, P.M., Yasumura, D., Weir, J., Matthes, M.T., Abderrahim, H., La Vail, M.M., Vollrath, D., 2000. Mutation of the receptor tyrosine kinase gene mertk in the retinal dystrophic RCS rat. Hum. Mol. Genet. 9, 645-651.

Dennis, P.B., Jaeschke, A., Saitoh, M., Fowler, B., Kozma, S.C., Thomas, G., 2001. Mammalian TOR: a homeostatic ATP sensor. Science 294, 1102-1105.

Dowling, J.E., Sidman, R.L., 1962. Inherited retinal dystrophy in the rat. J. Cell Biol. 14, 73-109.

Feng, D., Flaumenhaft, R., Bandeira-Melo, C., Weller, P., Dvorak, A., 2001. Ultrastructural localization of vesicle-associated membrane protein(s) to specialized membrane structures in human pericytes, vascular smooth muscle cells, endothelial cells, neutrophils, and eosinophils. J. Histochem. Cytochem. 49, 293-304.

Fischer, K., Chatterjee, D., Torrelles, J., Brennan, P.J., Kaufmann, S.H., Schaible, U.E., 2001. Mycobacterial lysocardiolipin is exported from phagosomes upon cleavage of cardiolipin by a macrophage-derived lysosomal phospholipase A2. J. Immunol. 167, 2187-2192.

Frantz, C., Coppola, T., Regazzi, R., 2002. Involvement of Rho GTPases and their effectors in the secretory process of PC12 cells. Exp. Cell Res. 273, 119-126.

Gagnon, E., Duclos, S., Rondeau, C., Chevet, E., Cameron, P.H., SteeleMortimer, O., Paiement, J., Bergeron, J.J., Desjardins, M., 2002. En- doplasmic reticulum-mediated phagocytosis is a mechanism of entry into macrophages. Cell 110, 119-131.

Gao, X., Zhang, Y., Arrazola, P., Hino, O., Kobayashi, T., Yeung, R.S., $\mathrm{Ru}$, B., Pan, D., 2002. Tsc tumour suppressor proteins antagonize amino-acid-TOR signaling. Nat. Cell Biol. 4, 699-704.

Garin, J., Diez, R., Kieffer, S., Dermine, J.F., Duclos, S., Gagnon, E., Sadoul, R., Rondeau, C., Desjardins, M., 2001. The phagosome proteome: insight into phagosome functions. J. Cell Biol. 152, 165-180.

Greenberg, S., Grinstein, S., 2002. Phagocytosis and innate immunity. Curr. Opin. Immunol. 14, 136-145.

Guo, Q.M., Malek, R.L., Kim, S., Chiao, C., He, M., Ruffy, M., Sanka, K., Lee, N.H., Dang, C.V., Liu, E.T., 2000. Identification of c-myc responsive genes using rat cDNA microarray. Cancer Res. 60, 5922-5528.

Hall, M.O., Abrams, T.A., 1987. Kinetic studies of rod outer segment binding and ingestion by cultured rat RPE cells. Exp. Eye Res. 45, 907-922.

Heller, R.A., Schena, M., Chai, A., Shalon, D., Bedilion, T., Gilmore, J., Woolley, D.E., Davis, R.W., 1997. Discovery and analysis of inflammatory disease-related genes using cDNA microarrays. Proc. Natl. Acad. Sci. USA 94, 2150-2155.

Henson, P.M., Bratton, D.L., Fadok, V.A., 2001. The phosphatidylserine receptor: a crucial molecular switch. Nat. Rev. Mol. Cell Biol. 2, $627-633$.

Herron, W.L., Riegel, B.W., Myers, O.E., Rubin, M.L., 1969. Retinal dystrophy in the rat: a pigment epithelial disease. Invest. Ophthalmol. 8, 595-604.

Ikeda, A., Hasegawa, K., Masaki, M., Moriguchi, T., Nishida, E., Kozutsumi, Y., Oka, S., Kawasaki, T., 2001. Mixed lineage kinase LZK forms a functional signaling complex with JIP-1, a scaffold protein of the c-Jun NH(2)-terminal kinase pathway. J. Biochem. 130, 773-781.

Inoki, K., Li, Y., Zhu, T., Wu, J., Guan, K.L., 2002. TSC2 is phosphorylated and inhibited by Akt and suppresses mTOR signalling. Nat. Cell Biol. 4, 648-657.

Ito, M., Tchoua, U., Okamoto, M., Tojo, H., 2002. Purification and properties of a phospholipase A2/Lipase preferring phosphatidic acid, Bis(monoacylglycerol) phosphate, and monoacylglycerol from rat testis. J. Biol. Chem. 277, 43674-43681.

La Vail, M.M., 1976. Rod outer segment disk shedding in the rat retina: relationship to cyclic lighting. Science 194, 1071-1074.

Liang, P., Pardee, A.B., 1992. Differential display of eukaryotic messenger RNA by means of the polymerase chain reaction. Science $257,967-$ 971.

Lipshutz, R.J., Fodor, S.P., Gingeras, T.R., Lockhart, D.J., 1999. High density synthetic oligonucleotide arrays. Nat. Genet. 2 (1 Suppl), $20-$ 24.

Mallard, F., Tang, B.L., Galli, T., Tenza, D., Saint-Pol, A., Yue, X., Antony, C., Hong, W., Goud, B., Johannes, L., 2002. Early/recycling endosomes-to-TGN transport involves two SNARE complexes and a Rab6 isoform. J. Cell Biol. 156, 653-664.

Mullen, R.J., LaVail, M.M., 1976. Inherited retinal dystrophy: primary defect in pigment xepithelium determined with experimental rat chimeras. Science 192, 799-801.

Nandrot, E., Dufour, E.M., Provost, A.C., Péquignot, M.O., Bonnel, S., Gogat, K., Marchant, D., Rouillac, C., Sépulchre de Condé, B., Bihoreau, M.-T., Shaver, C., Dufier, J.-L., Marsac, C., Lathrop, M., Menasche, M., Abitbol, M.M., 2000. Homozygous deletion in the coding sequence of the c-mer gene in RCS rats unravels general mechanisms of physiological cell adhesion and apoptosis. Neurobiol. Dis. 7, 586599.

Nihalani, D., Meyer, D., Pajni, S., Holzman, L.B., 2001. Mixed lineage kinase-dependent JNK activation is governed by interactions of scaffold protein JIP with MAPK module components. EMBO J. 20, 3447 3458 .

Perskvist, N., Roberg, K., Kulyte, A., Stendahl, O., 2002. Rab5a GTPase regulates fusion between pathogen-containing phagosomes and cytoplasmic organelles in human neutrophils. J. Cell Sci. 115, 1321-1330. 
Pierce, E.A., Quinn, T., Meehan, T., McGee, T.L., Berson, E.L., Dryja, T.P., 1999. Mutations in a gene encoding a new oxygen-regulated photoreceptor protein cause dominant retinitis pigmentosa. Nat. Genet. $22,248-254$

Puri, V., Watanabe, R., Singh, R.D., Dominguez, M., Brown, J.C., Wheatley, C.L., Marks, D.L., Pagano, R.E., 2001. Clathrin-dependent and -independent internalization of plasma membrane sphingolipids initiates two Golgi targeting pathways. J. Cell Biol. 154, 535-547.

Razani, B., Lisanti, M.P., 2001. Caveolin-deficient mice: insights into caveolar function human disease. J. Clin. Invest. 108, 1553-1561.

Schnitzer, J.E., Oh, P., McIntosh, D.P., 1996. Role of GTP hydrolysis in fission of caveolae directly from plasma membranes. Science 274 , $239-242$.

Strasser, J.E., Newman, S.L., Ciraolo, G.M., Morris, R.E., Howell, M.L., Dean, G.E., 1999. Regulation of the macrophage vacuolar ATPase and phagosome-lysosome fusion by Histoplasma capsulatum. J. Immunnol. $162,6148-6154$.
Swanson, J.A., Johnson, M.T., Beningo, K., Post, P., Mooseker, M., Araki, N., 1999. A contractile activity that closes phagosomes in macrophages. J. Cell Sci. 112, 307-316.

Uittenbogaard, A., Smart, E.J., 2000. Palmitoylation of caveolin-1 is required for cholesterol binding, chaperone complex formation, and rapid transport of cholesterol to caveolae. J. Biol. Chem. 275, 25595-25599.

Underhill, D.M., Ozinsky, A., 2002. Phagocytosis of microbes: complexity in action. Annu. Rev. Immunol. 20, 825-852.

Wasselius, J., Hakansson, K., Johansson, K., Abrahamson, M., Ehinger, B., 2001. Identification and localization of retinal cystatin C. Invest. Ophthalmol. Vis. Sci. 42, 1901-1906.

Waterman, H., Yarden, Y., 2001. Molecular mechanisms underlying endocytosis and sorting of ErbB receptor tyrosine kinases. FEBS Lett. 490, 142-152.

Zhao, Q., Morales, C.R., 2000. Identification of a novel sequence involved in lysosomal sorting of the sphingolipid activator protein prosaposin. J. Biol. Chem. 275, 24829-24839. 